NASA Technical Memorandum 105250

AIAA-91-3438

\title{
Plans for the Development of Cryogenic Engines for Space Exploration
}

James R. Stone and Loretta M. Shaw

Lewis Research Center

Cleveland, Ohio

and

Carl A. Aukerman

Sverdrup Technology, Inc.

Lewis Research Center Group

Brook Park, Ohio

Prepared for the

Conference on Advanced Space Exploration Initiative Technologies cosponsored by AIAA, NASA, and OAI

Cleveland, Ohio, September 4-6, 1991 


\title{
PLANS FOR THE DEVELOPMENT OF CRYOGENIC ENGINES FOR SPACE EXPLORATION
}

\author{
James R. Stone* and Loretta M. Shaw** \\ National Aeronautics and Space Administration \\ Lewis Research Center \\ Cleveland, Ohio 44135 \\ Carl A. Aukerman** \\ Sverdrup Technology, Inc. \\ Lewis Research Center Group \\ Brook Park, Ohio 44142
}

\begin{abstract}
The NASA Lewis Research Center (LeRC) is conducting a broad range of basic research and focused technology development activities in both aeronautical and space propulsion. By virtue of the successfull conduct of these programs, LeRC is strongly qualified to lead Advanced Development and subsequent development programs on cryogenic space propulsion systems in support of the Space Exploration Initiative (SEI). This paper provides a review of technology status, including recent progress in the ongoing activities, and a top level description of the proposed program.
\end{abstract}

\section{INTRODUCTION}

The planning activity described herein is offered in response to needs identified by the Advisory Committee On the Future of the U.S. Space Program (Ref. 1) and more recently the Synthesis Group on America's Space Exploration Initiative (Ref. 2), as well as numerous earlier studies (e.g., Ref. 3-9). The evolutionary development of the new hydrogen/oxygen (H/O) propulsion systems is proposed. Technologies being developed in the Exploration Technology Program for Lunar, Mars, and upper stage applications would be further advanced in an Advanced Development program, featuring pre-prototype testbeds, prior to the engine development. A strong Advanced Development program would provide significant reductions in the development program's cost and technical and schedular risk. Conducting these planned Technology and Advanced Development programs will assure the availability of mature, high performance options, qualified vendors and test facilities, experimentally verified component performance and computer codes, and a data base for technical, cost, and schedule assessments. The flight qualified propulsion systems developed according to this plan would meet the requirements for Lunar and Mars missions as well as orbit transfer applications (potentially including a Heavy Lift Launch Vehicle (HLLV) upper stage) well into the 21 st Century. For these vehicles, high performance and cost efficiency are key challenges that must be resolved for the Exploration Initiative. An advanced, high-performance engine, capable of being maintained in space, would enable reliable and reusable space-based vehicles for exploration. A focused program to develop space-based cryogenic engines is critical to all Exploration mission options involving space-basing and reusability of vehicles (Ref. 10).

\footnotetext{
* Associate Fellow, AIAA, **Member, AIAA

Copyright $(\odot) 1991$ by the American Institute of Aeronautics and Astronautics, Inc. No copyright is asserted in the United States under Title 17, U.S. code. The U.S. Government has a royalty-free license to excercise all rights under the copyright claimed herein for Government purposes. All other rights are reserved by the copyright owner.
} 


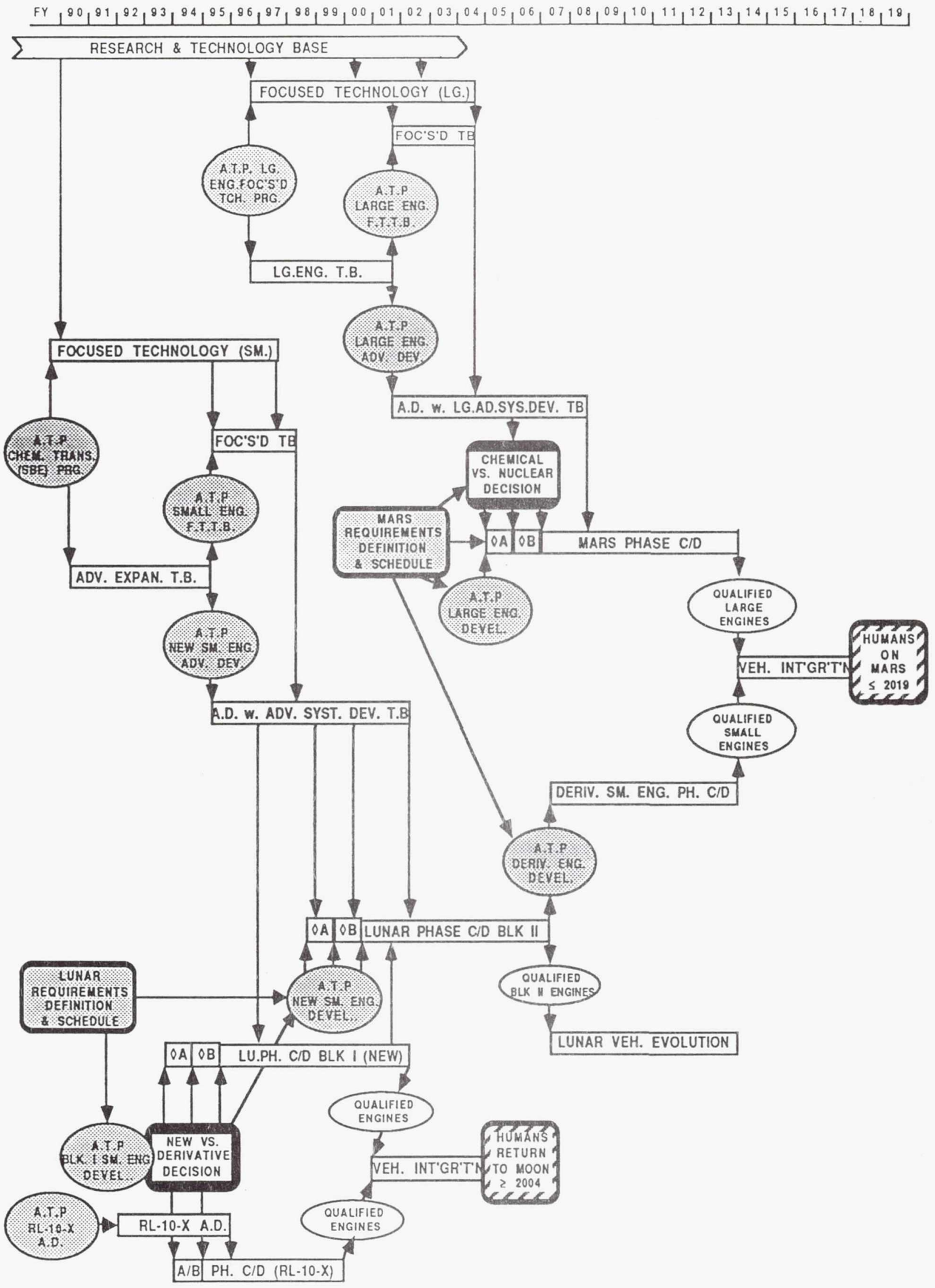

Figure 1-1 - Chemical Propulsion Overall Plan 
The Advisory Committee On the Future of the U.S. Space Program (Ref. 1) raised a number of concerns about the conduct of NASA programs, which will be addressed in formulating this plan. These include (1) overcommitment, (2) technology base, and (3) affordability. Our approach to dealing with these concerns is as follows:

(1) This plan will provide at the outset of the program for realistic estimates of needed resources and a management approach compatible with the uncertainties therein. Margins will be provided for goals, schedule, cost, and design concept.

(2) This plan proposes that development not be undertaken until a sufficient technological foundation, including needed facilities, is in place.

(3) Affordability will be enhanced by establishing a solid technology base before development is initiated; by developing accurate simulation models of the propulsion systems to maximize the amount of problem solving accomplished before building full-scale hardware, thereby minimizing the amount of redesign and retest, and allowing testing to be conducted more productively.

The planning focuses on the development of an evolutionary, flexible long-range plan that starts with $21 \mathrm{st}$ Century operations on Mars and works backward to critical initial steps and realistic budgets. The overall flow of this plan is shown in Figure 1. The bases for this plan's content and cost include the following:

(1) Industry plans and estimates,

(2) Lewis Research Center (LeRC) internal planning,

(3) LeRC technology program planning with the Office of Aeronautics, Exploration, and Technology (OAET),

(4) Technology and overall program discussions with the Marshall Space Flight Center (MSFC).

The discussions with MSFC helped to define a strategy for responding to schedule/ budget uncertainties.

\section{PROGRAM GOALS AND OB.IECTIVES}

The overall program will ultimately provide qualified H/O propulsion systems for space exploration vehicles and HLLV upper stages. The technology program will provide technologies sufficiently proven to allow the start of propulsion system development activities. The scope of the program will include the engine system, health management system, control system, and data management system, and may include the thrust vector control system, propellant tanks, feed system, reaction control system, and pressurant storage and delivery system.

OAET is currently studying several mission architectures, as discussed earlier, to provide recommendations and alternatives to support a national decision in the early 1990's on human exploration of the solar system (Refs. 7, 10-12). Preliminary general propulsion requirements for piloted exploration vehicles are shown in Figure 2. The Lunar Transfer Vehicle (LTV) engine must provide injection into lunar transfer trajectory from Low Earth Orbit (LEO) and injection into lunar orbit; engine out capability is desireable. The Lunar Excursion Vehicle (LEV) engines provide retropropulsion for lunar descent at vehicle thrust of 135 to $270 \mathrm{kN}$ (30-60 $\mathrm{klb}_{\mathrm{f}}$ ). This propulsion system must also throttle to 10-20 percent, dependent on configuration. After lunar operations, the LEV propulsion system provides ascent to lunar orbit (Ref. 13). LTV engines provide Earth-return injection, and aerobraking followed by a LTV engine burn to circularize is assumed upon return to Earth (Ref. 
14). More detailed preliminary requirements for the Lunar vehicles are listed in Table I. Additional requirements common to all propulsion systems include the following:

(1) High reliability, ruggedness, and fault tolerance,

(2) Space basing, long life (five uses with no major maintenance) and space maintainability,

(3) Man rating (Ref. 15),

(4) On-orbit check-out for reuse, and restart capability,

(5) Diagnostics (integrated controls and health monitoring),

(6) Some level of on-orbit assembly.

Critical design challenges for Lunar and Martian transfer and excursion vehicles include space-basing, high-thrust, throttling (for landers), reusability, and small engine size. Cryogenic hydrogen-oxygen propulsion system advancements for lunar transfer and excursion vehicle specific impulses of $476 \mathrm{sec}$ and $465 \mathrm{sec}$, respectively, are targeted for moderate-thrust (100 kN class) engines. Related developments for integrated, cryogenic attitude control thrusters will be required for the transfer vehicles along with, possibly, high-thrust $(1000 \mathrm{kN}$ class $)$ engines for the Trans-Mars Injection Stage (TMIS) (Ref. 10).

INITIAL OPERATIONAL CAPABILITY (IOC)

- MAN RATING

- HIGH RELIABILITY

- RUGGEDNESS

- ON-ORBIT CHECKOUT

- RESTART CAPABILITY

\section{LONGER TERM}

- AUTOMATED ON-ORBIT OPERATIONS

- REFUELING

- SERVICING

- PREFLIGHT CHECKOUT

- FAULT TOLERANCE

- LONG-LIFE SPACE BASING

- 5 USES WITH NO MAJOR MAINTENANCE

- SPACE MAINTENANCE

- DIAGNOSTICS

- INTEGRATED CONTROLS

- HEALTH MONITORING

- SOME LEVEL OF ON-ORBIT ASSEMBLY

Figure 2 -- Propulsion System Requirements for Exploration 
Flow Rate, $\mathrm{Ib}_{\mathrm{m}} / \mathrm{s}$

Chamber Pressure, psia

Mixture Ratio

Inlet Pressure,psia

Oxidizer

Fuel

Expansion Ratio

Throat Diameter, in

Exit Diameter, in

(Inside)

(Outside)

Engine Length, in

Stowed Length, in

Nozzle Length, in

Powerhead Length, in

Engine Mass, $\mathrm{lb}_{\mathrm{m}}$

Thrust-to-Weight Ratio

I sp Efficiency, percent $\underline{\text { LTV }}$

30

476

63.0

$\underline{\text { LEV }}$

30

465

64.4

1500

6

tb d

tbd

tbd

tbd

375

142

3.51

3.51

68

42

t b d

133

tbd

69

96

95

49

37

759

58

37

39.5

696

98.1
43.1

98.1

\section{TECHNICAL APPROACH}

Although the ultimate goal of development in support of these missions will be to provide reusable vehicles and systems, it may be necessary to perform the first missions with expendable hardware (Block I) and gradually evolve to reusability and space basing (Block II). The cryogenic propulsion program accounts for this evolutionary approach. In accordance with the recommendations of Reference 2, the emphasis will be placed first on safety, then on cost, performance, and schedule.

The Advanced Development programs would bring Advanced Space Engine technologies to an appropriate level to enable the start Phase C/D Design, Development, Test and Engineering (DDT\&E) of new engines to support the Space Exploration Initiative (SEI) and other upper stage applications, including those of commercial interest. This activity would focus on both the $100 \mathrm{kN}$ (for transfer and excursion vehicles) and $1000 \mathrm{kN}$ (trans-Mars injection and large upper stage) classes.

A parallel (and optional) RL-10 derivative development program is proposed to 
provide the capability to support near-term missions with relatively low cost and low technical/schedular risk. Early iteration with users would provide the performance and life goals; current planning is for $67-134 \mathrm{kN}$ thrust, with $\mathrm{I}_{\mathrm{sp}}>460 \mathrm{sec}$, throttling capability, and reuse up to 190 firings or 5 hours of operating life.

One of the keys to reducing cost is to minimize the propellant mass required in LEO to perform the mission. Launch of the many million pounds required for virtually all future space exploration mission scenarios may be affordable only if advanced propulsion systems can be made available (Ref. 4). Reduced propellant requirements in orbit translate to substantial cost savings because fewer Earth-to-orbit (ETO) vehicle launches are required to accomplish the mission. For example, in the case of a manned Mars mission, an increase of $35 \mathrm{sec}$ in engine specific impulse $\left(\mathrm{I}_{\mathrm{sp}}\right)$ may eliminate the need for two ETO vehicle launches. A key enabling technology to reduce LEO propellant requirements is the development and use of high-performance $\mathrm{LH}_{2} / \mathrm{LO}_{2}$ engines (Ref. 10).

Another key to reduced cost is to develop and utilize reusable stages that are based in and operated from LEO. Technologies that will enable automated in-orbit operations (e.g., refueling, maintenance, servicing, and preflight checkout, as well as fault tolerant operation) are crucial to the successful development and use of space-based vehicle systems. Integrated controls and health monitoring systems will be required for such fault tolerant engines, which will be used repeatedly and maintained in space (Refs. 11, 16-17). Computational modeling (Refs. 18-20) and probabalistic analysis (e.g., Refs. 21-22) have a high potential to identify problems and potential solutions prior to hardware fabrication and test. Thus hardware costs should be reduced, testing made more productive, and better understanding developed of test results than traditional "cut-and-try" methods.

\section{TRADITIONAL SPACE ENGINE PHILOSOPHY}

- EXPENDABLE VEHICLES

- USE PREVIOUS DESIGN EXPERIENCE TO THE MAXIMUM

- ARBITRARY REQUIREMENTS FOR QUALIFICATION

- LONG-DURATION, COSTLY TESTING REQUIRED

- "CUT AND TRY" APPROACH DID NOT ALWAYS CONVERGE ON HIGHLY RELIABLE, OPTIMUM DESIGNS

Figure 3 - Traditional Space Engine Design Philosophy 
Recent studies of the operational efficiency of propulsion systems (e.g., Ref. 23) have shown that a modular approach to propulsion system design may be beneficial. In such an approach there is cross-coupling between components instead of multiple independent engines. For example there may be more pumps than combustion chambers with a plenum between, and all the combustion chambers could feed a common nozzle, perhaps a plug nozzle (e.g., Ref. 24). Such an approach offers advantages in flexibility and could enable the development of different thrust level systems with savings in development, production and operations obtainable by using the same components. However, in addition to the obvious need to consider the system interactions, there are potential problems which may offset these benefits, for example maintainability problems, especially when space-based, if high pressure lines, joints and interfaces must be broken, and where additional valving may be required for redundancy (Ref. 25).

In any case space basing will be a very challenging problem, especially since the only nearer term space-based vehicle development, the Orbital Maneuvering Vehicle (OMV), has been cancelled.

\section{MANAGEMENT PLAN}

This is a project which the Lewis Research Center (LeRC) is strongly positioned to lead because of its demonstrated expertise in space and aeronautical propulsion. The work would be performed by LeRC with support from other NASA field centers. Propulsion system testing may involve support from the Marshall Space Flight Center (MSFC). In utilizing a Total Quality Management approach the support would be required from the Kennedy Space Center (KSC) in the operations and preflight preparations area, from the Johnson Space Flight Center (JSC) in manned missions, and from the Jet Propulsion Laboratory (JPL) in robotic missions. In keeping with the recommendations of Reference 1, the day-to-day project management will be conducted by the lead field center. Having the propulsion system and vehicle managed at different field centers can help surface issues and provides checks and balances.

\section{TECHNICAL PLAN}

The historical "test oriented" development process (Fig. 3) has a number of undesirable characteristics:

(1) Arbitrary requirements for qualification,

(2) Extensive system testing required for qualification,

(3) Does not necessarily converge on high reliability,

(4) Does not necessarily converge on an optimum design,

(5) Does not necessarily converge on a solution,

(6) Requires system testing long after qualification.

One of us (Aukerman) served on a team which reviewed lessons learned from the Space Shuttle Main Engine (SSME) development program, the first development of reusable engines, which has proven to be an exceptionally challenging problem. Some of the key findings from that study are shown in Figures 4-6. The test-oriented approach requires large amounts of testing for all components, whether complex or simple, as illustrated in Figure 4. Even more disturbing is the observation that reliability, as measured by failure rate does not necessarily improve as more testing is accomplished, as shown in Figure 5. Another drawback of the test-oriented approach is that testing continues long after qualification, as shown in Figure 6 for both space and aeronautical propulsion. 


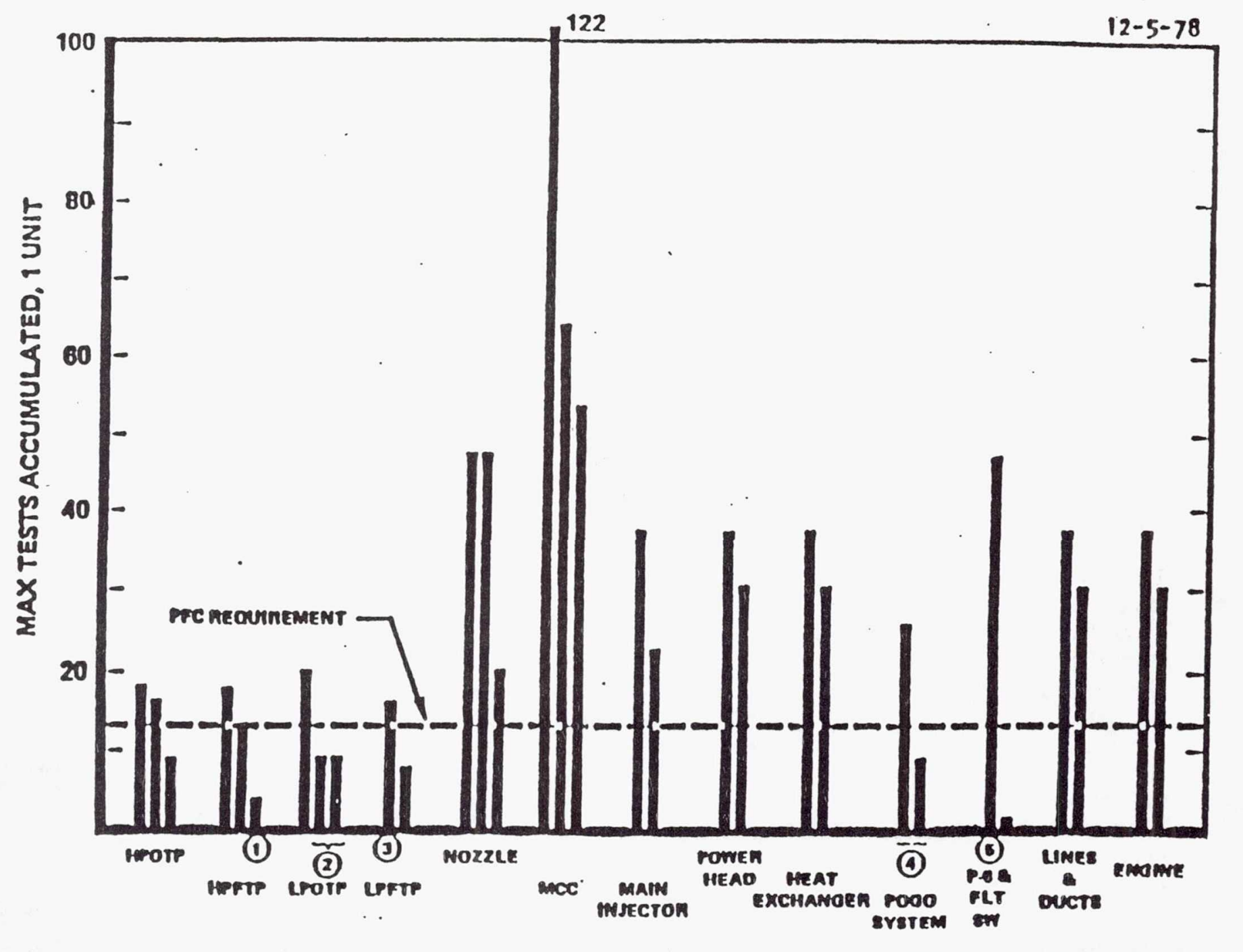

\section{QUALIFICATION OF COMPLEX COMPONENTS NO DIFFERENT THAN SIMPLE COMPONENTS}

Figure 4 - First Manned Orbital Flight (FMOF) Engine

Configurations Tested (From Rocketdyne).

Because of these deficiencies (Fig. 7) in a test-oriented approach, LeRC proposes a system level "knowledge based" approach for development of these families of propulsion systems (Fig. 8). A multidisciplinary effort is underway to develop modeling capability (Fig. 9) at the component level in both aeronautical and space propulsion and at the system level in aeronautics (Ref. 17). The emerging methodologies are presently being applied to the SSME durability effort and will now be applied to space transfer engines (Fig. 10).

What remains to be accomplished in order to confidently proceed with the development of an advanced, high-performance, expander cycle engine for future space missions is the validation testing of engine components, testing of these components assembled into an engine system (to study component interactions, system transients, system dynamics, and health monitoring/control systems), and the 
verification of analytical design models/codes at both the engine component and engine system level. The Pathfinder Chemical Transfer Program (renamed the Exploration Technology Space-Based Engine Program, Ref. 11) is intended to elevate technology readiness (to Level 6 as shown in Figure 11) to bridge the gap between basic research and technology (R\&T) efforts and the advanced development of the engines.

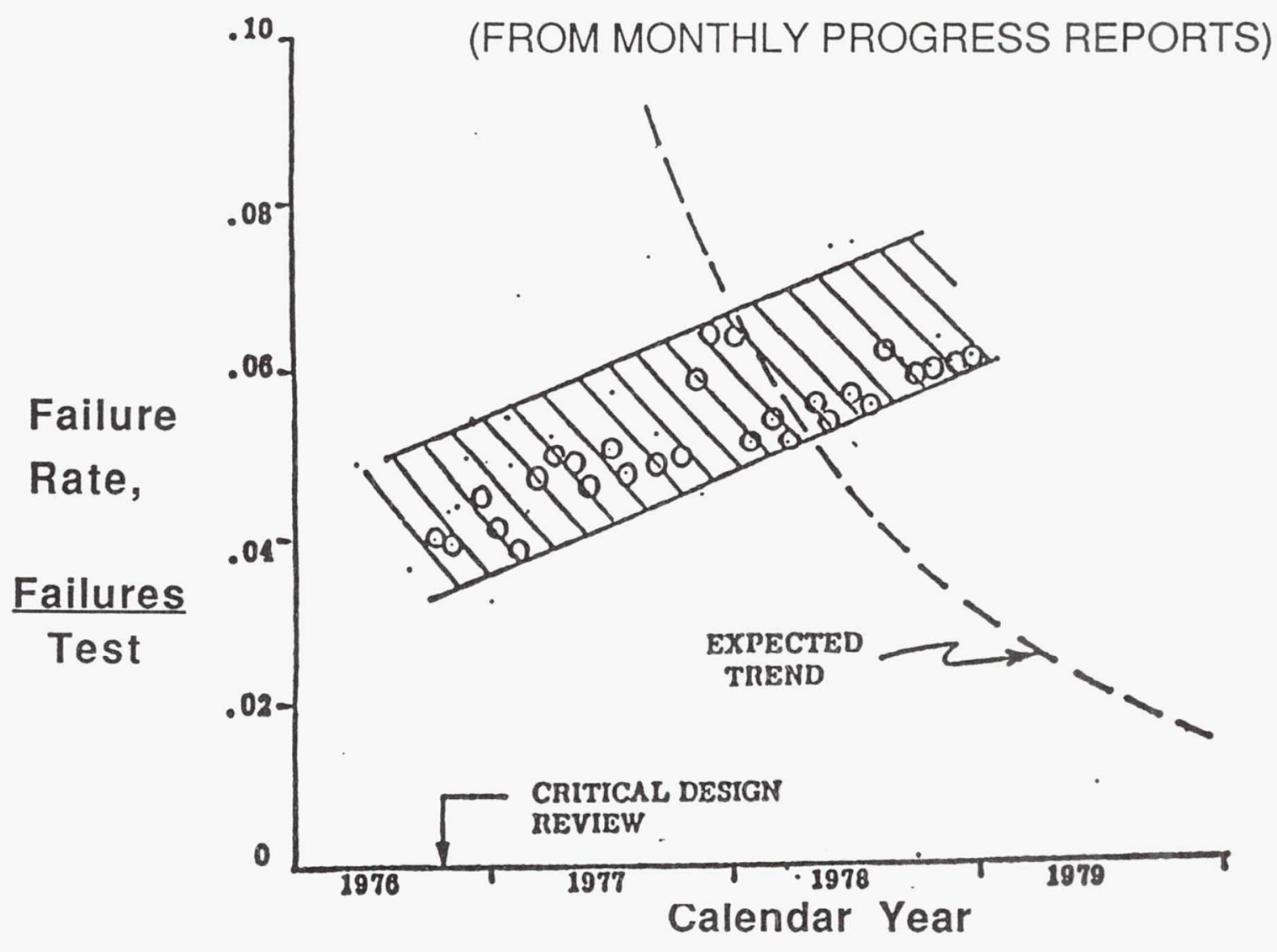

\section{TEST ORIENTED DEVELOPMENT DOES NOT NECESSARILY CONVERGE ON HIGH RELIABILITY}

Figure 5 - Space Shuttle Main Propulsion System (MPS)

Development Testing and Qualification. SSME Failures per Test.

\section{Transfer Vehicle Primary Propulsion}

The first propulsion system requiring advanced development and development is the 100-kN class for the Lunar Transfer Vehicle (LTV) and the Mars Transfer Vehicle (MTV). This advanced development and development programs would be supported by ongoing Focused Technology and Advanced Engine Test Bed Programs. To reduce program risk, RL-10 derivitive engines would be maintained as a back-up option for LTV and LEV engines. Decisions on the commonality between LTV and LEV engines and on RL-10 options would be made by the end of the Advanced Development phase. The strong technology program prior to and during the engine development program will enable significant reductions in the cost of the development program and increased precision in the estimates and control of the development program. 
This approach will provide the DDT\&E decision makers with mature, high performance options; qualified component vendors and test facilities; experimentally verified component performance and computer codes; and a data base for technical, cost, and schedular risk assessments.

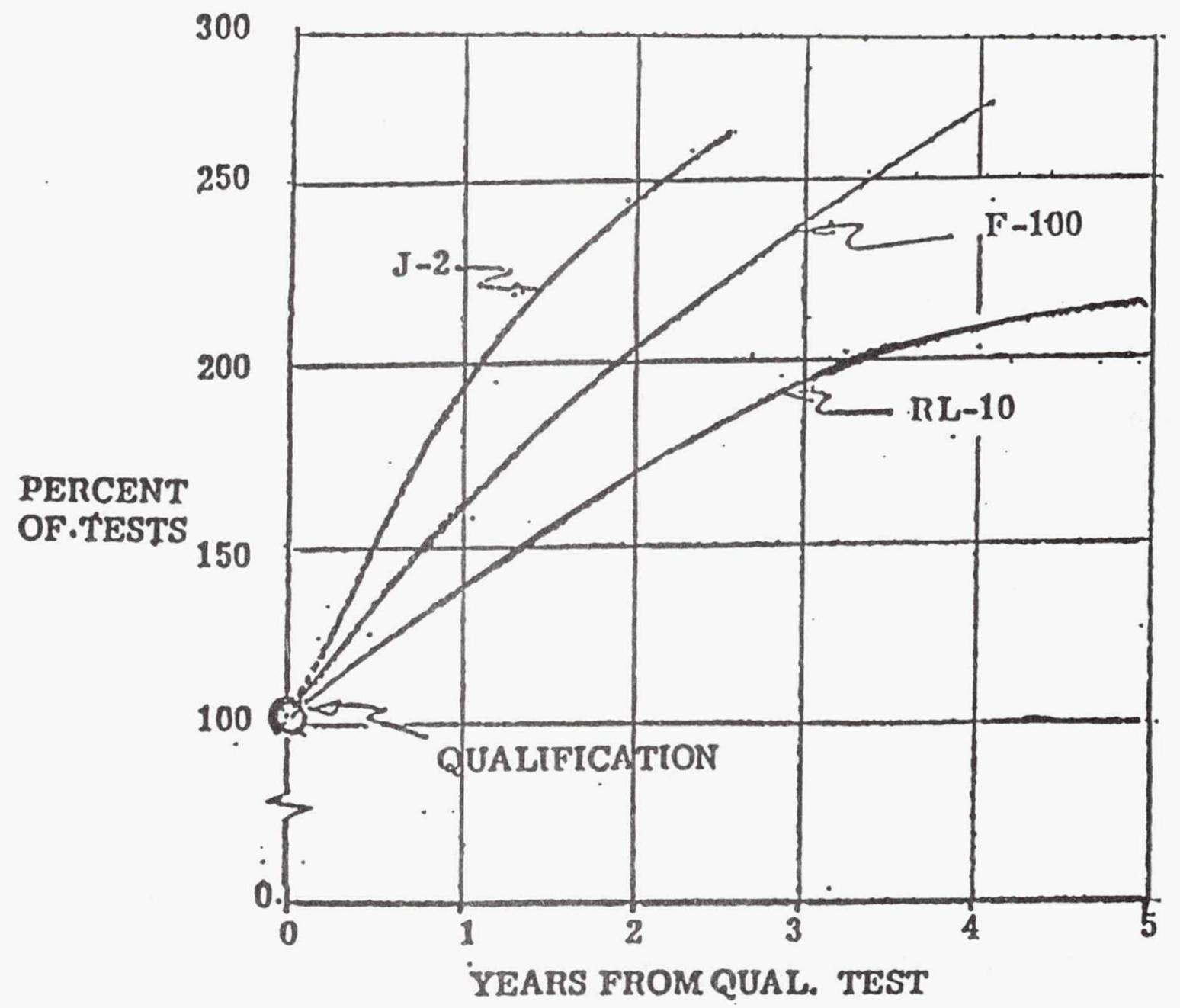

\section{TESTING CONTINUES LONG AFTER QUALIFICATION}

Figure 6 - MPS Post Qualification Improvement.

Post Qualification Testing History.

\section{Integrated $\mathrm{H}_{2} \mathrm{LO}_{2}$ - Auxiliary Propulsion}

LeRC conducted an Advanced Development program for Space Station Freedom propulsion. For the high-thrust $(110-220 \mathrm{~N})$ function, gaseous $\mathrm{H} / \mathrm{O}$ thrusters were investigated (e.g., Ref. 26). Studies conducted at LeRC have shown that advanced auxiliary propulsion subsystems (APS) can significantly increase the payload of advanced ETO vehicles (Refs. 27-28). Similar benefits should also be available to space transfer vehicles (Ref. 29). Advanced development and development on these systems can start about a year after the primary propulsion activity. 
- MULTIDISCIPLINARY OPTIMIZATION DEMANDS A PROHIBITIVE AMOUNT OF TESTING TO ESTABLISH CONFIDENCE

- $\quad$ PREVIOUS DESIGN EXPERIENCE DOES NOT EXIST FOR NEW REQUIREMENTS

Figure 7 - The Problem

REQUIRES ENGINE SYSTEM MODEL TO INTEGRATE FLUID DYNAMICS, STRUCTURAL DYNAMICS, AND PERFORMANCE

\section{REQUIRES DEFINABLE OPTIMIZATION CRITERIA FOR CHARACTERISTICS}

\section{REQUIRES VERIFIED ANALYSIS/MODELS TO TOTALLY DEFINE ENGINE BEHAVIOR AND TO REDUCE TESTING TO MANAGEABLE LEVELS}

\section{MULTI-DISCIPLINARY OPTIMIZATION REQUIRED \\ - SYSTEMS APPROACH \\ - TOTAL QUALITY MANAGEMENT}

Figure 8 - Knowledge Based Design Approach

\section{Trans-Mars Injection Stage Engines}

Large, $1000 \mathrm{kN}(\sim 220 \mathrm{klb})$ cryogenic $\left(\mathrm{LH}_{2} / \mathrm{LO}_{2}\right)$ engines have been identified as back-up to nuclear thermal propulsion for enabling for the Trans-Mars Injection Stage (TMIS) (Ref. 2). Specific requirements for this engine are not yet defined; further definition of the engine mission characteristics is required. System studies of competing engine cycles will be needed to determine scalability, mission suitability, and cost trades. Cryogenic engines will be needed for Mars Transfer Vehicles (MTVs) and Mars Excursion Vehicles (MEVs). As shown in Figure 1, at some point a decision must be made as to whether new engines of this size will be needed. 


\section{SIMULATION:}

- $\quad$ COMPUTER ENVIRONMENT

- MULTIDISCIPLINARY MODULES

- VERIFIED COMPONENT CODES

- PROBABILISTIC ANALYSIS

\section{OPTIMIZATION:}

\section{- EXPERT SYSTEM INTERACTION}

- "COMPUTATIONAL" ENGINE RESEARCH

- $\quad$ ENGINE SYSTEM OPTIMIZATION

Figure 9 - Computational Engine Simulator/Optimizer

\section{State-of-the-Art Assessment}

The only upper stage $\mathrm{LH}_{2} / \mathrm{LO}_{2}$ engine currently in operation is the RL-10 expander cycle engine, which was developed and certified in the late 1950's and early 1960's. The RL-10A-3-3A engine, the specifications for which are given in Table II, represents the current state of the art. Two of these engines are used on the Atlas Centaur vehicle. The RL-10A-3-3A is a regeneratively cooled, turbopump-fed rocket engine with limited throttling capability (at significant performance loss) and no on-board diagnostics. It was designed for and has only been used on expendable vehicles and is not compatible with future demands for performance, reusability, man rating, fault tolerant operation, and in-space mainenance (Ref. 30). Later investments in RL-10 technology resulted in modest improvements $\left(\mathrm{I}_{\mathrm{sp}}=459.8 \mathrm{sec}\right.$ for the derivative RL-10-IIB at a mixture ratio of 6.0 using a 205:1 area ratio boilerplate nozzle) (Ref. 11).

A $91 \mathrm{kN}\left(20.5 \mathrm{klb}_{\mathrm{f}}\right)$ derivative $\mathrm{RL}-10$, the RL10A-4 has recently been developed by Pratt \& Whitney under contract to General Dynamics to enhance performance of Atlas $2 \mathrm{~A}$ and $2 \mathrm{~A} / \mathrm{S}$ launch vehicles (Ref. 31). It features a new $\mathrm{LO}_{2}$ pump and new extendable nozzle to improve $I_{s p}$. 


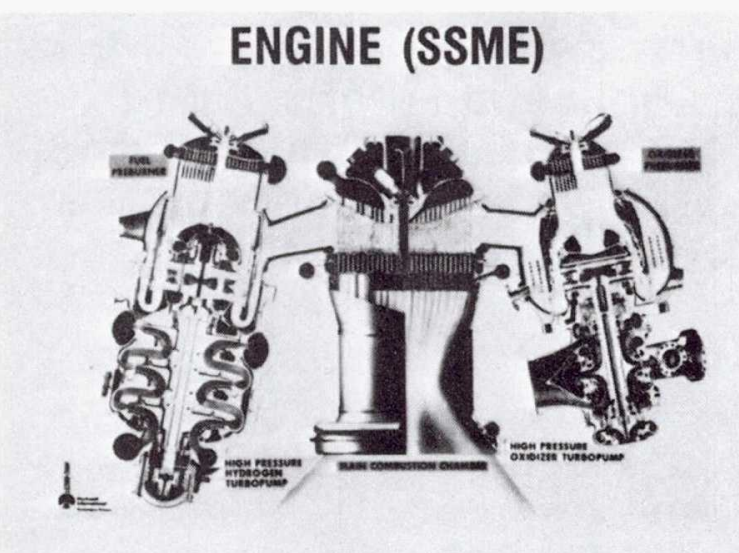

COMPUTATIONAL FLUID DYNAMICS (BLADE PRESSURES)

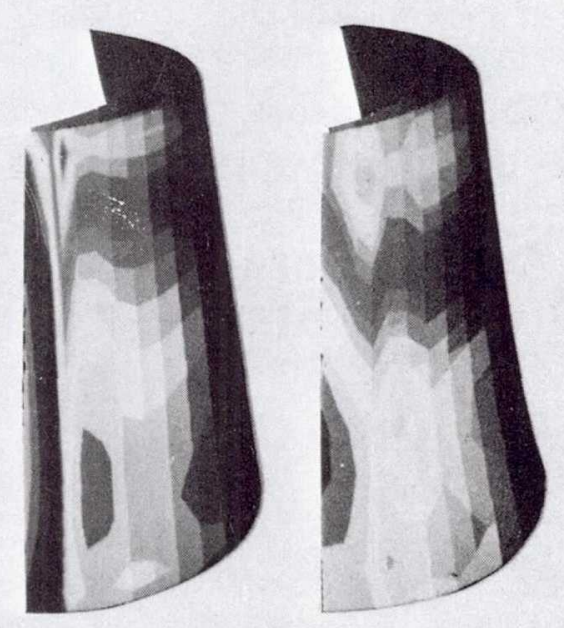

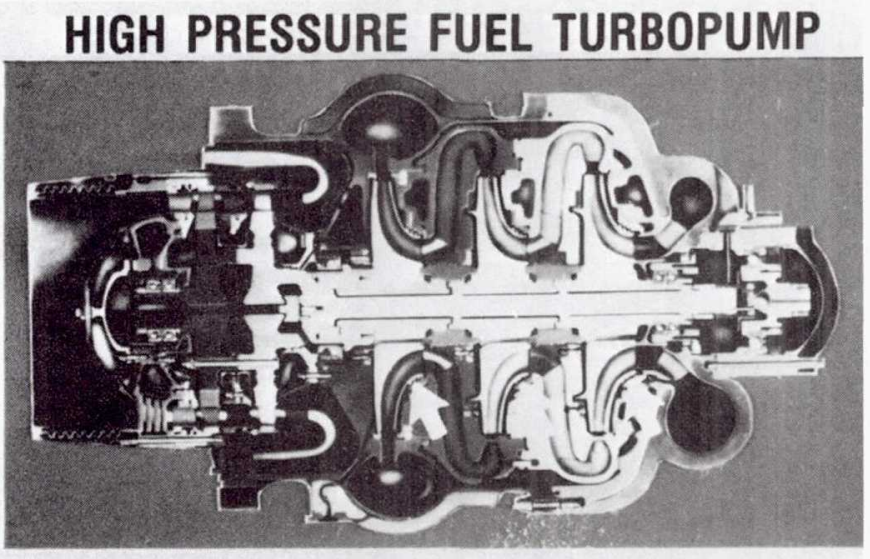

\section{COMPUTATIONAL STRUCTURAL} ANALYSIS

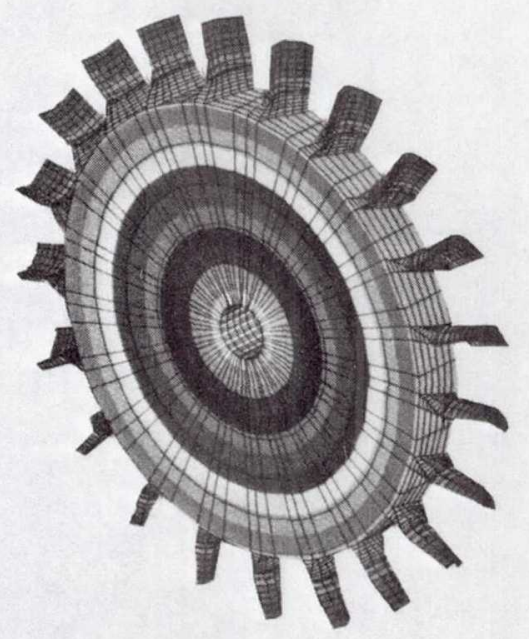

CD $-89-44191$

Figure 10 - Computational Engine Simulator

The RL-10A-3-3A cannot perform to the requirements of the LTV or LEV, as currently understood. Significant new development time and resources would be required to provide the throttling, man rating, and performance necessary to accomplish the baseline mission. Although throttling over a 10:1 range has been demonstrated at LeRC, additional components are required, and instability issues must be resolved. The RL-10 contains numerous single point or Category 1 failure modes that must be resolved and qualified for the engine to be utilized in a man-rated system. To date, the RL-10 has not demonstrated a nozzle extension to provide the desired performance. The low pressure levels of the RL-10 result in an engine size which makes packaging into the LTV or LEV difficult (Ref. 13). 


\section{Level Description}

Technology Development

1. Basic Principles Observed and Reported.

2. Technology Concept/Application Formulated.

3. Analytical and Experimental Critical Function and/or Characteristic Proof-of-Concept.

4. Component and/or Breadboard Validation in Laboratory.

5. Component and/or Breadboard Demonstrated in Relevant Environment.

6. System Validation Model Demonstrated in Relevant/Simulated Environment.

7. System Validation Model Demonstrated in Actual Environment.

\section{Advanced Development}

8. Technology Applied to Construction of Component and/or Breadboard of Expected Flight Hardware Configuration.

9. Capability of Full Scale Subsystem Prototype Demonstrated in Ground Tests.

10. Capability of Full Scale Subsystem Prototype Demonstrated in Actual Use.

\section{Flight Hardware Development}

11. Full Scale System Prototype.

12. Capability Demonstrated in Flight Test of Flight Hardware.

13. Capability Demonstrated by Operational Flight Experience.

Figure 11 -- Technology Maturation Milestones.

In the early 1970's NASA initiated a technology program directed toward an advanced $\mathrm{LH}_{2} / \mathrm{LO}_{2}$ upper stage engine. The program initially focused on an advanced space engine utilizing a staged combustion cycle for very high pressure, high performance operation. The Advanced Space Engine Technology Program was carried through component verification testing, at which time it was decided that an expander cycle engine would better satisfy future mission requirements. The Orbital Transfer Rocket Engine Technology Program, which began in the early 1980's focused on advanced component technologies for high performance (high pressure), 
reusable $\mathrm{LH}_{2} / \mathrm{LO}_{2}$ expander cycle engines which would be space based and man rated. Efforts focused on technologies for high speed turbomachinery, high heat transfer combustors, large area ratio nozzles, and health monitoring systems to address these longer term technology goals. The basic proof-of-concept of advanced, high performance expander cycle components was the aim of this program. Some limited testing of turbomachinery and health monitoring components in a breadboard engine and design studies for a flight version of this breadboard (RS-44) were also conducted (Ref. 11).

\section{Table II -- RL-10 Specifications}

\section{Parameter}

Propellant

Mixture Ratio $(\mathrm{O} / \mathrm{H})$

Combustion Pressure

Power Cycle

Vacuum Thrust

Thrust Throttling Ratio

Vacuum Specific Impulse

Nozzle Area Ratio

Total Impulse

Life - Operational

- Service Free

Electric Power Required

Mass

Length

Basing

Human Rating

Design Criteria

\author{
required
}

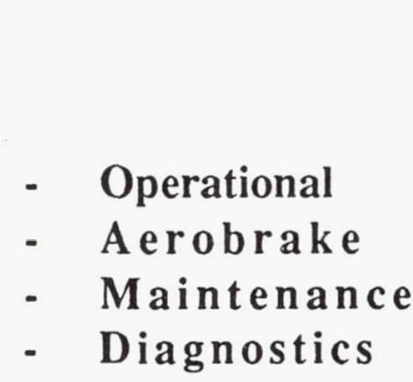

Hydrogen/Oxygen

5.0 (design)

4.4-5.6 range

465 psia (design)

Expander

16.5 klbf (design) Vacuum

Not specified

444.4 lbf-sec/lbm

$61: 1$

66 Mlbf-sec

3 starts, $4000 \mathrm{sec}$

Not specified

Minimal

$310 \mathrm{lbm}$

70.1 in.

Earth

No

Not specified

None

Not specified

None

The Technology Program was carried through component verification testing, at which time it was decided that an expander cycle engine would better satisfy future mission requirements. The Orbital Transfer Rocket Engine Technology Program, which began in the early 1980's focused on advanced component technologies for high performance (high pressure), reusable $\mathrm{LH}_{2} / \mathrm{LO}_{2}$ expander cycle engines which would be space based and man rated. Efforts focused on technologies for high speed turbomachinery, high heat transfer combustors, large area ratio nozzles, and health monitoring systems to address these longer term technology goals. The basic proof-of-concept of advanced, high performance expander cycle components was the aim of this program. Some limited testing of turbomachinery and health monitoring components in a breadboard engine and design studies for a flight version of this breadboard (RS-44) were also conducted (Ref. 11). 
Figure 1 gives an overall relative schedule and key milestones for the project. Table III briefly describes the potential deliverables and a relative schedule for the proposed Advanced Development / Development program and indicates how this schedule, including its options supports various possible Space Exploration Initiative (SEI) architectures.

The program will focus first on small (100 kN class) engines to support lunar, and possibly Mars transfer and excursion vehicles, then on the auxiliary propulsion systems for these vehicles, and finally on large (1000 kN class) engines potentially applicable to a Trans-Mars Injection Stage (TMIS) and to a range of upper stages including those of commercial interest. The impact of the possible earlier development of a HLLV upperstage propulsion system has not yet been taken into account.

\section{Table III - Deliverables \\ (Relative time frame)}

Approx.

FY

DELIVERABLE

2000 Block I LTV Prototype Engine

Block I LEV Prototype Engine

Prototype LTV Auxiliary Propulsion System

Prototype LEV Auxiliary Propulsion System

2001 Block I LTV Engine Certification

Block I LEV Engine Certification

LTV Auxiliary Propulsion System Certification

LEV Auxiliary Propulsion System Certification

2002 Block II LTV Prototype Engine

Block II LEV Prototype Engine

Block II LTV Engine Certification

2003 Block II LEV Engine Certification

2014 MTV Prototype Engine

MEV Prototype Engine

Prototype MTV Auxiliary Propulsion System

Prototype MEV Auxiliary Propulsion System

2015 MTV Engine Certification

MEV Engine Certification

MTV Auxiliary Propulsion System Certification

MEV Auxiliary Propulsion System Certification 


\section{STATUS}

High performance cryogenic propulsion technology development is under way in the Exploration Technology Program (formerly Pathfinder) and Propulsion Base R\&T Programs. (Ref. 32). The Pathfinder Program supports both the Focused Technology and Advanced Engine Test Bed (AETB) Programs (Refs. 33-34). Operational capability exists in the RL-10 engine product line. The Space-Based Engines (Technology) Program will formulate design methodologies for advanced, space-based engines and implementation of multiple ground-based, advanced, expander-cycle cryogenic engine testbeds, including developments of components for deep throttling, health monitoring, space servicing and aerobrake-compatible (expendable) nozzles. This program will continue work begun in the Pathfinder Program, conducted by the Lewis Research Center and several major industry participants (Ref. 11). The AETB, to be delivered in 1996, is designed for $111 \mathrm{kN}\left(25 \mathrm{klb}_{\mathrm{f}}\right)$ thrust, $1500 \mathrm{psi}$ chamber pressure, and $I_{\mathrm{sp}}=480 \mathrm{sec}$, but will be tested at $89 \mathrm{kN}$ thrust, 1200 psi chamber pressure, and $I_{\mathrm{sp}}=480 \mathrm{sec}$. Thus it is labled an $89 \mathrm{kN}\left(20 \mathrm{klb}_{\mathrm{f}}\right)$ thrust test bed engine with throttling capability from 5 to $125 \%$ capability.

The Advanced Development and Development programs are still in the discussion and planning stage.

\section{CONCLUDING REMARKS}

The NASA Lewis Research Center, with inputs from the NASA Marshall Space Flight Center and the industry, has developed a plan to develop cryogenic space propulsion systems for the Space Exploration Initiative. The program will focus first on small (100 kN class) engines to support lunar, and possibly Mars transfer and excursion vehicles, then on the auxiliary propulsion systems for these vehicles, and finally on large (1000 kN class) engines potentially applicable to a Trans-Mars Injection Stage (TMIS) and to a range of upper stages including those of commercial interest. A system level "knowledge based" approach for development of these families of propulsion systems will be used. A multidisciplinary effort is underway to develop modeling capability at the component level in both aeronautical and space propulsion and at the system level in aeronautics. The emerging methodologies are presently being applied to the SSME durability effort and will be applied to space transfer engines.

\section{Acknowledgement}

The authors would like to thank the many people at Lewis, other government facilities, industry, and academia, who helped in this activity by participating in our internal and external workshops. Special thanks go to William Tabata and others in the Space Vehicle Propulsion Branch at Lewis and to Jerry Redus, Lee Jones and John Cramer of the MSFC Propulsion Laboratory.

\section{REFERENCES}

1. "Report of the Advisory Committee On the Future of the U.S. Space Program," Dec. 1990.

2. "America at the Threshold," Report of the Synthesis Group on America's Space Exploration Initiative, May 1991.

3. "Report of the 90-Day Study on Human Exploration of the Moon and Mars," NASA, Nov. 1989.

4. "Space Technology to Meet Future Needs," Committee on Advanced Space 
Technology, Aeronautics and Space Engineering Board, Commission on Engineering and Technical Systems, National Research Council, National Academy Press, Washington, DC, 1987.

5. Reck, G.M., "NASA Directions in Space Propulsion for 2000 and Beyond," NASA TM-102281, Mar. 1989.

6. Jahn, R.G., et al., "On to the Solar System," The Report of the Ad Hoc Review Team on Lunar and Planetary Propulsion Requirements of the Space Systems and Technology Advisory Committee for NASA, March 10, 1989.

7. "Beyond Earth's Boundaries -- Human Exploration of the Solar System in the 21st Century," 1988 Annual Report to the Administrator, Office of Exploration, NASA, Dec. 1988.

8. "Exploration Studies Technical Report - FY 1988 Status - Volume I: Technical Status," NASA TM 4075, Dec. 1988.

9. "Exploration Studies Technical Report - FY 1988 Status - Volume II: Study Approach and Results," NASA TM 4075, Dec. 1988.

10. Mankins, J.C., and Buoni, C.M., "Technology and Mars Exploration," AIAA Paper 90-3797, AIAA Space Programs and Technologies Conference, Huntsville, AL, Sept. $25-27,1990$.

11. Hannum, N.P., Berkopec, F.D., and Zurawski, R.L., "NASA's Chemical Transfer Propulsion Program for Pathfinder," AIAA Paper 89-2298, July 1988 (also NASA TM-102298).

12. "Technology Needs for Human Exploration Missions - 1989 Interim Assessment," Doc. Z-89-1.2-001, Mar. 1989.

13. Aukerman, C.A., "A White Paper - A Comparison of Propulsion Systems for Lunar Transfer and Lunar Excursion Vehicles - The Advanced Space Engine and RL-10A-3-3A," NASA Lewis Research Center, Aug.-Sept. 1989.

14. "Lunar/Mars Outpost," Program Development Presentation, NASA Geo. C. Marshall Space Flight Center, Sept. 11, 1989.

15. Cerimele, M.P., "Guidelines for Man Rating Space Systems," JSC-23211, Dec. 28,1988 .

16. Millis, M.G., "Technology Readiness Assessment of Space Based Engine Integrated Control and Health Monitoring." AIAA Paper 91-3601, NASA/AIAA/OAI Conference on Advanced SEI Technologies, Cleveland, OH, Sept. 4-6, 1991.

17. Bickford, R.L., and Gage, M.L., "Technology Assessment for an Orbit Transfer Rocket Engine Integrated Control and Health Mcnitoring System." AIAA Paper 91-3606, NASA/AIAA/OAI Conference on Advanced SEI Technologies, Cleveland, OH, Sept. 4-6, 1991.

18. Nichols, L.D. , "Numerical Propulsion System Simulation: an Interdisciplinary Approach," AIAA Paper 91-3554, NASA/AIAA/OAI Conference on Advanced SEI Technologies, Cleveland, OH, Sept. 4-6, 1991.

19. Veres, J.P., "CFD Analysis of a Crossover Diffuser Within a Centrifugal Pump." AIAA Paper 91-3555, NASA/AIAA/OAI Conference on Advanced SEI Technologies, Cleveland, OH, Sept. 4-6, 1991. 
20. Felder, J.L., and Binder, M., "Modelling Requirements for Space-Based Engine Research and Technology." AIAA Paper 91-3556, NASA/AIAA/OAI Conference on Advanced SEI Technologies, Cleveland, OH, Sept. 4-6, 1991.

21. Newell, J.F., and Rajagopal, K.R., "Probabilistic Methodology -- A Design Tool for the Future," Threshold, No.5, Rockwell International, Rocketdyne Division, Fall 1989, pp. 30-37.

22. Cruse, Thomas W., "Designing for Uncertainty," Aerospace America, Vol. 26, No. 11, Nov. 1988, pp.36-39.

23. Wong, G.S., Fredricks, J.E., Fulton, D.L., Ingle, W.B., and Waldrop, G.S., "Operationally Efficient O2/H2 Propulsion Module for Advanced Launch Systems," AIAA Paper 90-2432, 26th AIAA/SAE/ASME/ASEE Joint Propulsion Conference, Orlando, FL, July 16-18, 1990.

24. Aukerman, C. A., "Integrated Modular Engine Applications," AIAA Paper 91-3485, NASA/AIAA/OAI Conference on Advanced SEI Technologies, Cleveland, OH, Sept. 4-6, 1991.

25. Tabata, W.K., NASA Lewis Research Center, Personal Communication, 1990.

26. Jones, R.E., Meng, P.R., Schneider, S.J., Sovey, J.S., and Tacina, R.R., "Space Station Propulsion System Technology," Acta Astronautica, Vol. 15, No. 9, Sept. 1987.

27. Schneider, S.J., "Auxiliary Propulsion Technology for Advanced Earth-to-Orbit Vehicles," JANNAF Propulsion Conference, San Diego, CA, Dec. 1987 (also NASA TM-100237).

28. Schneider, S.J., and Reed, B.D., "Weight Savings in Aerospace Vehicles through Propellant Scavenging," SAWE Paper 1818 (Index Category No. 24), Presented at 47th Annual Conference of the Society of Allied Weight Engineers, Inc., Plymouth, MI, May 1988.

29. Reed, B.D., and Schneider, S.J., "Hydrogen/Oxygen Auxiliary Propulsion Technology for the Space Transfer Vehicle." AIAA Paper 91-3440, NASA/AIAA/OAI Conference on Advanced SEI Technologies, Cleveland, OH, Sept. 4-6, 1991.

30. "RL-10 Liquid Rocket Engine Service Manual: Model RL-10A-3-3A," United Technologies, Pratt and Whitney Aircraft Group, Feb. 15, 1982.

31. "Pratt \& Whitney Finishes Advanced Rocket Testing," Space News, May 21-27, 1990, p.19.

32. Berkopec, F.D., and Hemminger, J.A. "Status of the Space-Based Engine Program," AIAA Paper 91-3436, NASA/AIAA/OAI Conference on Advanced SEI Technologies, Cleveland, OH, Sept. 4-6, 1991.

33. Masters, A.I., and Tabata, W.K., "Design of an Advanced Expander Test Bed." AIAA Paper 91-3437, NASA/AIAA/OAI Conference on Advanced SEI Technologies, Cleveland, OH, Sept. 4-6, 1991.

34. "Advanced Expander Test Bed Program. Preliminary Design Review Report, " Pratt \& Whitney, West Palm Beach, FL, May 1991 (NASA CR-187081). 
Public reporting burden for this collection of information is estimated to average 1 hour per response, including the time for reviewing instructions, searching existing data sources, gathering and maintaining the data needed, and completing and reviewing the collection of information. Send comments regarding this burden estimate or any other aspect of this allocion Davis Highway, Suite 1204, Arlington, VA 22202-4302, and to the Office of Management and Budget, Paperwork Reduction Project (0704-0188), Washington, DC 20503.

\begin{tabular}{|l|l|l}
\hline 1. AGENCY USE ONLY (Leave blank) & $\begin{array}{c}\text { 2. REPORT DATE } \\
\text { September 1991 }\end{array}$ & $\begin{array}{r}\text { 3. REPORT TYPE AND DATES COVERED } \\
\text { Technical Memorandum }\end{array}$
\end{tabular}

\section{TITLE AND SUBTITLE}

Plans for the Development of Cryogenic Engines for Space Exploration

\section{6. $\operatorname{AUTHOR}(\mathrm{S})$}

James R. Stone, Loretta M. Shaw, and Carl A. Aukerman
5. FUNDING NUMBERS

WU-591-41-41
8. PERFORMING ORGANIZATION REPORT NUMBER

E-6579

Lewis Research Center

Cleveland, Ohio 44135 - 3191

10. SPONSORING/MONITORING AGENCY REPORT NUMBER

National Aeronautics and Space Administration

Washington, D.C. 20546-0001

NASA TM-105250

AIAA-91-3438

11. SUPPLEMENTARY NOTES

Prepared for the Conference on Advanced Space Exploration Initiative Technologies cosponsored by AIAA, NASA, and OAI, Cleveland, Ohio, September 4-6, 1991. James R. Stone and Loretta M. Shaw, NASA Lewis Research Center; Carl A. Aukerman, Sverdrup Technology, Inc., Lewis Research Center Group, 2001 Aerospace Parkway, Brook Park, Ohio 44142. Responsible person, James R. Stone, (216) $977-7120$.

12a. DISTRIBUTION/AVAILABILITY STATEMENT

Unclassified-Unlimited

Subject Category 20 12b. DISTRIBUTION CODE

13. ABSTRACT (Maximum 200 words)

The NASA Lewis Research Center (LeRC) is conducting a broad range of basic research and focused technology development activities in both aeronautical and space propulsion. By virtue of the successful conduct of these programs, LeRC is strongly qualified to lead Advanced Development and subsequent development programs on cryogenic space propulsion systems in support of the Space Exploration Initiative (SEI). This paper provides a review of technology status, including recent progress in the ongoing activities, and a top level description of the proposed program.

\section{SUBJECT TERMS}

Space-based propulsion; Cryogenic propulsion; H/O propulsion; Integrated auxiliary propulsion

15. NUMBER OF PAGES

20

16. PRICE CODE

$$
\mathrm{A03}
$$

\begin{tabular}{|c|c|}
\hline $\begin{array}{c}\text { 17. SECURITY CLASSIFICATION } \\
\text { OF REPORT }\end{array}$ & $\begin{array}{c}\text { 18. SECURITY CLASSIFICATION } \\
\text { OF THIS PAGE } \\
\text { Unclassified }\end{array}$ \\
\begin{tabular}{c} 
Unclassified \\
\hline
\end{tabular}
\end{tabular}

19. SECURITY CLASSIFICATION OF ABSTRACT Unclassified 